John Carroll University

Carroll Collected

2019

Words, Pictures, and the "Nonlistening Space": Visual Design and Popular Music as Forms of Performance in First-Year Writing

Maria Lynn Soriano

Follow this and additional works at: https://collected.jcu.edu/fac_bib_2019

Part of the Creative Writing Commons, and the Rhetoric and Composition Commons 


\title{
Words, Pictures, and the "Nonlistening Space": Visual Design and Popular Music as Forms of Performance in First- Year Writing
}

\author{
Maria Soriano
}

\begin{abstract}
The chapter focuses on the importance of teaching visual rhetoric by examining a multimodal first-year writing course unit that asks students to create concert posters for their favorite bands or musical artists. In addition, students produce explanatory essays that translate their creation process into words, representing their imaginations on paper. Soriano discusses the ways that this unit has improved and enriched the writing of many of her students, including poster examples and supplemental materials for instructors who might want to adopt this assignment and challenge their students to invade their own "nonlistening spaces."
\end{abstract}

\section{Introduction: Forms of Rhetoric at War}

In the 2013 film Words and Pictures, English teacher Jack Marcus challenges art instructor Dina Delsanto with the following powerful question: "Words versus pictures: which is worth more?" (Schepisi, 2014). Exploration, creation, and arguments ensue between the students of Marcus and Delsanto as they compose written and visual pieces that simultaneously unite and separate the persuasive components of written and visual rhetoric. These performances highlight the necessity of studying rhetoric, for as Joan Mullin (2011) argued, "in its study of how communication takes place and is received, rhetoric is relevant as a useful tool for research in all arts practices since, in addition to the medium of language, the original components of ancient rhetorical practice include the purposeful use of voice, tone, performance, and visual effect" (p. 152). Students first learn of these principles in their English classes between grades 9-12 because of the curricular emphasis on proficiency in explanatory writing, and continue to develop them in college-level first-year writing (FYW) courses. They examine and articulate detailed arguments supported by research, and learn to direct those messages to a chosen audience- primarily through writing. But as more FYW curricula incorporate multimodal assignments, lessons on written and visual rhetoric (or, words and pictures) are juxtaposed in order to examine the performative power of each genre. 
What is gained by studying visual rhetoric in FYW? Cultural awareness, for one, because we are immersed in visual rhetoric: television commercials, magazine ads, political postcards, and electronic banners on the side of computer, tablet, and phone screens, just to name a few. Because of this constant exposure, teaching visual rhetoric alongside writing in FYW is crucial for the development of students' capacities to negotiate the world because, as Carolyn Handa (2004) wrote, "Visual rhetoric in the composition course then serves two ends: to help students better understand how images persuade on their own terms and in the context of multimodal texts, and to help students make more rhetorically informed decisions as they compose visual genres" (p. 3). To accomplish these objectives, I focus in this chapter on using popular music and visual design to teach visual rhetoric in my FYW course by adding aural learning and perception into my pedagogy. By provoking students to actively tune in to the music and lyrics that play in the backgrounds of their workouts, study sessions, and walks between classes, I aim to engage their imaginations and teach them to transpose sounds into pictures, creating concert posters that advertise their chosen bands and artists. Next, they translate the visual element into words, writing detailed explanatory essays that function as evidence-based rationales for their design choices and represent intentionality, a key component of metacognitive development. By separating and then uniting visual and written rhetoric through the lessons and assignments of this unit, students learn to understand academic projects as performative acts-an objective that is enhanced through the use of popular music.

\section{Process: Classroom Instruction and Unit Overview}

Craig Stroupe (2004) asserted the necessity of including visual arts in the pedagogy of FYW when he wrote that "words don't simply talk to words, but to images, links, horizontal lines-to every feature of the iconographic page" (p. 25). In her chapter, Faith Kurtyka (2015) cited Barbara Duffelmeyer and Anthony Ellertson, who also believed that students need to learn "critical visual literacy," or the ability to understand visuals not as a direct representation of reality, but as constructed from a certain viewpoint. To teach this essential principle in the classroom, I begin the visual rhetoric unit by addressing the following question, posed best by Charles $\mathrm{A}$. Hill (2004): "How, exactly, do images persuade? In other words, how do representational images work to influence the beliefs, attitudes, opinions - and sometimes actions-of those who view them?" (p. 25).

Advertisements are an ideal genre to examine as my students begin to answer Hill's question. From magazines and newspapers to Twitter feeds and Facebook pages, advertisements reach out to us so frequently that we often ignore, overlook, and scroll past them. Therefore, my first step is to get students to actually look at 
some advertisements, record reactions, and analyze design strategies: photos and graphics; font size, type, and placement; colors; audience; and intended messages. Next, I prompt students to consider the reasons why each ad's creators made specific choices with each element of the design. The final introductory lesson focuses on the genre of concert posters, drawing conclusions about how the elements represent the band or artist, the style of music, the location, and the concert atmosphere. These initial lessons introduce students to the study of visual rhetoric and teach them to narrowly focus on each element of a poster, deepening their critical thinking and analysis skills as they determine the impact of that designer's choices. ${ }^{1}$ Such scrutiny and synthesis demonstrate that in visual design, intentionality is key-every element is carefully chosen and contributes to the piece as a whole. ${ }^{2}$

The unconscious acceptance of and distanced subscription to some elements of the world that surround us every day (like advertisements) represent a frame of mind that Cynthia and Richard Selfe labelled a "nonthinking space" (Stroupe, 2004, p. 17). Similarly, we often listen to but simultaneously tune out our favorite music, shifting it behind primary thoughts and tasks without interference, so applying the Selfes' term to music produces what I call a "nonlistening space." Judging by the number of college students I see with earbuds practically glued into their ears as they study, work out, or walk, I knew that tapping into that passive, "nonlistening space" to teach visual rhetoric would be meaningful and relatable. In his essay about music in the FYW classroom, Scott Strovas (2011) discussed the effectiveness of the topic: "I have found music to be a useful course topic in advancing more important writing objectives such as learning to think critically and to engage primary source materials effectively. Writing about music reinforces the importance of writing descriptively, which in turn empowers students to trust in their own perceptions and develop an individual writing voice," (p. 25) an observation that supports my own ideas. To echo Strovas, I believe that a carefully constructed visual rhetoric unit encourages students to actively engage with an element in their lives that is familiar, and consequently enhances the development of both critical thinking and explanatory writing.

After we complete the introductory lessons, students begin to design their posters. To aid invention and record research, sources, and ideas, I provide students with a worksheet (found in Appendix A) that divides the process into stages—-similar to the writing process that FYW teachers (and others across the disciplines) implement for written papers and projects. During the research and active listening stages of the project, I encourage my students to listen exclusively to the music of

1 See Kurtyka (2015), who also posited in her study of sorority social media sites, "students may need guidance in exploring the possibilities of arrangement in digital media to make a variety of associations, beyond just what is cool at any given moment."

2 The chapter on elements of visual rhetoric in any edition of Everything's an Argument (by Andrea A. Lunsford and John J. Ruszkiewicz) is particularly helpful in providing students with detailed background material for this unit. 
their chosen bands or musical artists while they work in class for an immersive, connected experience. They first conduct research on the bands or artists, gathering information on the histories, musical influences, discographies, evolution, and even charitable causes and organizations that the musicians created or support. That research forms a foundation for both aspects of the project and gives them credibility as creators and writers.

Because the students in FYW courses at the private, liberal arts university where I teach bring diverse experiences with and knowledge about music into my classroom, I incorporate some basic music theory into the unit (in addition to the basic principles of design that I mentioned earlier) to help them listen more actively to the band or musical artist they choose to focus on. ${ }^{3}$ Similar to the multiple layers and elements contained within an advertisement or concert poster, music weaves together multiple instrumental and vocal tracks that the "nonlistening" mind does not always notice. Active listening requires students to listen to songs and albums multiple times, which challenges them to consciously tune in to the songs and tune out their surroundings to deconstruct the music.

Once they determine that their initial research is complete and have made notes from listening to the music (sometimes narrowing the focus to one particular album), the students move to the third step of the process: making connections and engaging their imaginations. I provoke them to think of colors, words, scenes, locations, moods, or "vibes" - a term I borrow from Kurtyka (2015)— that they picture as they listen to the music, especially since "images enhance our ability to understand and feel music" (Walters, 2010, p. 17). One section of their worksheets makes space for them to record their thoughts; the material generated in the listening moment will help them intentionally choose words and pictures when they begin to create their posters. As they connect aural sounds with visual images, they implicitly learn the concept of intertextuality, where "images, sounds, and spatial delineations are read on to and through one another" (Rogoff, 2004, p. 381). This concept manifests itself in the individualized associations each student makes when listening to his or her music.

When they are ready to transform their ideas and notes into a concrete design, the students turn to their "easels." Though I offer students the chance to draw, paint, or make prints for their posters, most use Microsoft PowerPoint or Adobe Photoshop on their computers to edit images and add or manipulate text. In more recent years, some students have used apps on their tablets to select and edit photos, text, and graphics. As an instructor, observing my students during in-class workshop days is as fascinating as seeing the final products; not only do I learn more about them from their tastes in music and their posters-in-progress, but

3 I provide my students with brief definitions of the following musical concepts: instrumentation, effects, mood, lyrics, tone, dynamics, rhythm, riff, key change, and tempo. We also discuss how these concepts connect, aided by the method sheet in Appendix A. 
I also see their projects evolve. They select and change fine details over and over, rarely asking for my input; only they can determine what looks "right," from the precise shade of blue to the exact style of font. ${ }^{4}$ I have watched a student try every font style in the Microsoft Office Suite, examining a preview of each to determine which suited his poster best. Similarly, I also watched a student spend 30 minutes rotating and resizing a photo in order to get the placement and proportions to her liking. Such a critical eye and attention to exact detail, as well as a sense of "play" with digital media, is crucial for their posters—and, I tell them, for their writing. ${ }^{5}$

\section{Product: Project Results}

\section{Concert Posters}

Because we identify genres of music or specific bands or artists as our "favorites" for various reasons-connections to friends or family, memories of concerts, relatable lyrics, or appealing voices or instrumentation - the opportunity for students to work in-depth with music enhances their levels of investment. The dual-performance environment of visual rhetoric and traditional academic writing turns the FYW classroom into a design studio, where students work quietly and individually, each with their own blank canvas (the computer screen). Their posters outwardly reflect their imaginations and their identities — which are not shaped or influenced by others during the creation process. ${ }^{6}$ At the conclusion of the unit, I project each student's poster on the overhead; here, the students "perform" for their peers by displaying and discussing their creations. Their enthusiasm reflects their pride in and ownership of their projects, and they applaud and admire the work of their peers as well.

To illustrate the components and results of this assignment, I include a few student examples on the following pages. These posters reflect each student's musical taste and connection with the band or artist, as well as their knowledge of technology and design tools. To begin, Mike's poster for Jeff the Brotherhood is below:

4 Mullin (2011) explained this critical, artistic precision: "A designer might intuit or think rhetorically to more quickly understand that while yellow is the colour she wants, lemon yellow does not create the effect desired" (p. 154).

5 Sohui Lee and Russell Carpenter (2015) incorporated the idea of academic creativity in the form of play into their chapter: "Play allowed students to freely experiment with visual and mediated elements, to make mistakes, and to try new combinations while learning about how these decisions affect the design of a text."

6 Students do receive feedback on their posters during the unit's peer review session; their peers evaluate the effectiveness of the poster based on readability, arrangement, colors, fonts, and relative sizes in accordance with our early lessons. 




Figure 6.1. Mike's poster for Jeff the Brotherhood (courtesy of Mike Campbell).

Mike's advanced experience with PowerPoint and Photoshop contributes to his deceivingly complex poster design. The background image is a screen-captured frame from a Jeff the Brotherhood music video. Then, from a separate image of the two band members, Mike used his laptop touchpad to trace the outline of their bodies, layering the edited image onto the background. Finally, he created his own font by drawing individual lines to form the angles and shapes of the text. Mike's design choices, articulated in his explanatory essay, visually correspond with Jeff the Brotherhood's laidback, mellow sound (the musicians only play guitar and drums, but produce songs with big, complex melodies and rhythms) and emit a relaxed and carefree vibe. Mike's selection of an outdoor scene also reflects the duo's preference for playing at outdoor venues, which incorporates "expert" information that he learned during the research stage. Similar to the music of Jeff the Brotherhood, Mike's poster appears simple—but actually incorporates many intentional and informed design choices and techniques that demonstrate his critical visual literacy.

Equally successful for different reasons, the next example represents a creative use of digital resources, combining images and graphics found online with fonts available in Microsoft PowerPoint.

7 All student posters and survey answers are reproduced in this chapter with the students' written permission. 


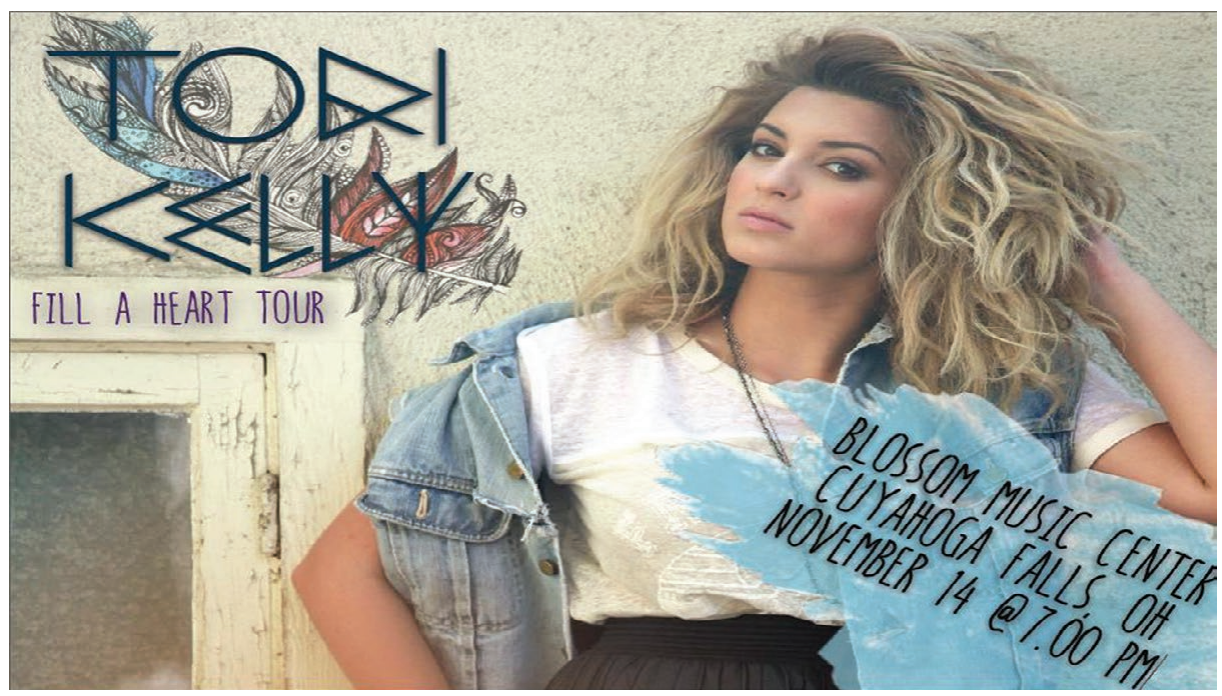

Figure 6.2. Mylane's poster for Tori Kelly (courtesy of Mylane Bella-Smuts).

Mylane's poster for Tori Kelly features carefully and thoughtfully chosen fonts and graphics, as well as a soft, faded color scheme that corresponds with Tori Kelly's indie, light pop music and airy vocals. Similar to Mike, Mylane intentionally layered images and text on her poster, demonstrating her understanding of one of my lessons on visual design. Mylane first selected a background image of Tori Kelly, and then placed complementary graphics (the feather and the watercolor splash) onto that background so she could clearly position the important text on top of those images as her last step. The font sizes strategically draw the viewer's eyes all the way from the top left of the poster to the bottom right - a technique that reflects an in-class lesson on strategic placement as a marketing technique to ensure that readers see and read every aspect of the poster. Though Mylane has never attended a Tori Kelly concert, she extracted ideas from the music and lyrics and used her imagination to construct the experience. To me, Mylane's poster effectively balances words and pictures, demonstrating how the two types of rhetoric can be equally persuasive and complementary.

Similar to Mylane's poster, the last student example also incorporates elements of visual and written rhetoric; however, the difference with Kasey's poster is that she used images and formatting (as well as descriptions in her essay) gathered from first-hand experiences.

For the background, Kasey chose a photo that she took at a Periphery show and manipulated the shadow effects, adding a red filter over the black and white tint. She incorporated the band's font and logo in the top left and lower right corners, and then added the (imaginary) concert details. The most impressive aspect 
of Kasey's project is her credibility as the designer, which is revealed in her essay. Kasey frequently attends concerts at The Agora (a small venue in Cleveland, Ohio) and collects show posters and advertisements; during her design process, she took note of certain standards across her collection that the venue uses in all of its advertisements, and replicated those standards in her own design (I do wish that she had included some examples in her essay for my benefit). Since Kasey was a marketing major, I was pleased that she treated this assignment like a professional experience - and combined that with ideas and memories from the concerts she previously attended. Her writing, as a result, was both vivid and confident.

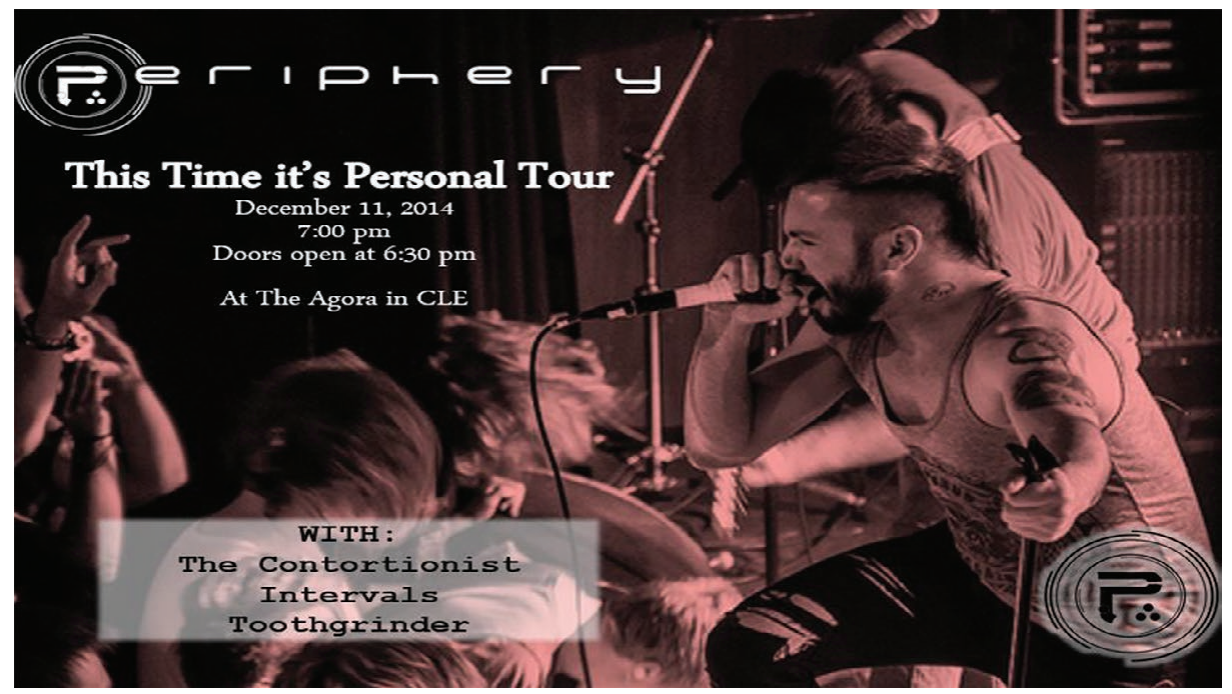

Figure 6.3. Kasey's poster for Periphery (courtesy of Kasey Gilson).

Whether students create their posters solely from their imaginations or use the assignment as an opportunity to relive concerts they attended, the results bring them closer to the music they listen to on a daily basis. Students who focus on bands or artists that they have seen live draw upon both their imaginations and their memories - and these vivid memories contribute to beautiful posters and well-written essays, like Kasey's project. On this topic, Catherine L. Hobbs (2004) wrote, "The faculty of imagination, intertwined with memory, becomes central to the very definition of rhetoric, which carries with it a cognitive model. It forms the background of discoveries in vision and optics and is linked with the notion that we gain knowledge through observation" (p. 61). Whether or not they are creating and writing from their own memories, the explanatory essay aspect of the project "provides students a chance to develop and gain trust in their writing abilities while exploring what their favorite music means to them" (Strovas, 2011, p. 33). Visually representing that meaning enhances their connection and personal investment, and 
the use of visual design and music encourages students to invest the time that is necessary to produce a successful project.

\section{Explanatory Essays}

In addition to the posters that engage their imaginations and concert memories, many students produce their strongest writing of the semester in this unit. They initially balk at the "lengthy" page requirements (included on the assignment sheet in Appendix B), but easily reach (and exceed) those requirements when they begin to explain every detail of their posters after completing the visual element of the unit. In her article, Anicca Cox (2015) questioned, "What does it mean to use writing to create or inform the process of 'doing' or 'making' in visual or performing arts practices?" To add to her inquiry, I ask, "What does it mean to use writing to transpose the process of 'making' visual art?" To me, it means a key to metacognition and a window to the imagination. Learning to perform a "close writing" that maintains a narrow focus on one small detail at a time teaches students to enhance their persuasiveness and choose their words precisely. As a result, their writing is more thoroughly developed and convincing to the audience-one rhetorical canon emphasized by Lee and Carpenter (2015).

To show an example of the vivid, descriptive writing that emerges in students' explanatory essays, I include the introduction of Alex's explanatory essay about The National, reproduced with his permission. Alex began the semester as a disinterested writer, struggling with focus and development in his argument analysis and research-based written assignments during the first half of the semester (for which he earned average grades). The visual rhetoric unit, in contrast, gave Alex the opportunity to recreate his experience attending The National's concert-an assignment that opened the door for him to access and connect with writing and language on a deeper, more meaningful level. Without my guidance or influence in early drafts, Alex's final essay included the following introduction:

As the crowd walks into the concert hall, there is an atmosphere to resemble space not based on appearance but something deeper than that. Amidst the black background of the stage, blue, purple, and white lights flash to give the image of something more than just a stage during the concert, but going to a whole new place entirely, a different world. When the five members of the band walk out into this different world, this is when the audience is truly brought into what is happening. Matt Berninger, the singer, steps out among the two sets of brothers, Scott Devendorf who plays the bass and his brother Bryan who plays the drums. Behind them Aaron Dessener and his brother 
Bryce, both guitar players, step out to the stage to perform for the always eager audience. The lights dim and the crowd cheers as the blue lights cover the crowd for the display of light that will captivate them and instill a memory for years to come. The performance begins and now the audience has entered the complex, dark, and smooth rhythm of the rock band before them.

From Alex's incorporation of sensory details (the flashing blue, purple, and white lights) to his narration of the order the band members walk onto the stage, readers are fully immersed in this concert environment-and therefore, in his embodied experience. We feel the same excitement and anticipation as the audience members because of the mental image Alex's words communicate to our minds.

In addition to these vivid images, Alex's precise rhetorical choices in his essay correspond with the photos and color scheme on his poster, which demonstrates his close attention to his poster during his writing process to ensure that both elements complemented each other.

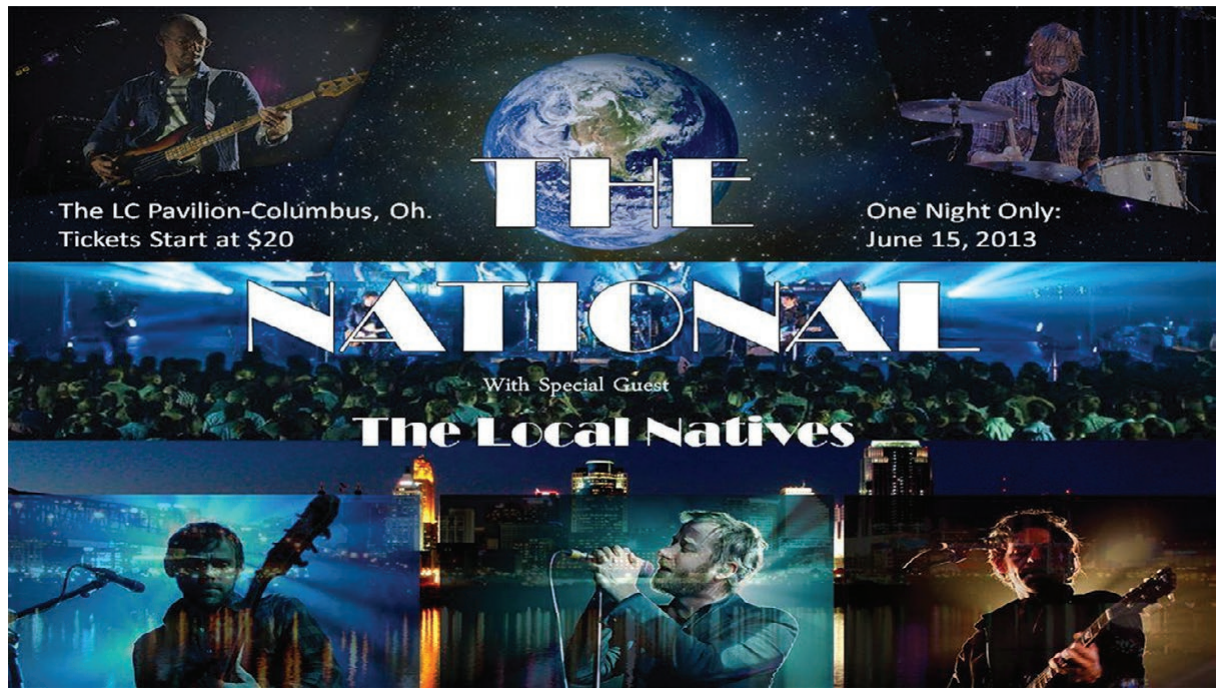

Figure 6.4. Alex's poster for The National (courtesy of Alex Zamblauskas).

Most importantly_for me as an instructor and for Alex as a first-year writerthis markedly improved writing revealed that Alex successfully synthesized and applied important lessons about academic writing, earning an A for the project. Because he had the chance to write about music (and, further, music that he loved and knew well), he easily incorporated the principles of clear, descriptive writing and logical representation of both his research and the scenes he imagined when he created his poster. Like Alex, many of my students have produced stronger, more cohesive writing as a result of this unit, which is accompanied by in-class lessons on 
research, paragraph development, and source incorporation between weeks 6 and 10. By the time they are working on their portfolios five weeks later, they are able to revise assignments from earlier in the semester with a deepened sense of critical thinking and strengthened ability to connect with the audience.

Though the concert poster is created first for this unit, the explanatory essay carries equal weight. The students must explain every design choice, specifically articulating the reasons they chose each image, font, color, and object placement. This writing challenge forces them to focus on every detail and use language that precisely represents what they imagined, connecting those details to an overall argumentative statement that their posters effectively represent their bands or artists. Through metacognitive reflection on their posters and articulation of their rationale for each decision, students absorb larger lessons on academic writing that can then be replicated in writing across the disciplines-a feature of what Lee and Carpenter (2015), as well as James Purdy (2014), cited as "design thinking pedago-

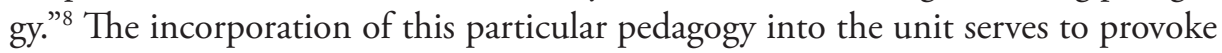
knowledge and skill transfer across courses; a student learns to articulate the reasons she selected a particular photo of Beyoncé, for example, and therefore transfers that lesson to Philosophy papers, where her opinions and ideas need just as much detail and clear support.

Similar to the traditional written research paper, this unit also requires students to locate relevant evidence and incorporate that into both their posters and essays. Some students research color theory and corresponding feelings or emotions when creating their posters, and then cite the evidence they locate in their essays as support. Others use information about the bands or artists in their designs and essays. For example, Alexa included the logo for Bama Works, a fund established and maintained by Dave Matthews Band, in the top right corner of her poster. She then incorporated information about the Fund in her essay, explaining its purpose and importance to the musicians.

$8 \quad$ For further explanation, see James P. Purdy's (2014) "What Can Design Thinking Offer Writing Studies?" I found his use of the verbs design and compose intriguing in the context of my assignment, as both verbs have longitudinal connotations. Specific to the context of writing, compose seems more linear, while design seems more freeform and movement-oriented (as with the digital creation process of "pictures"). 


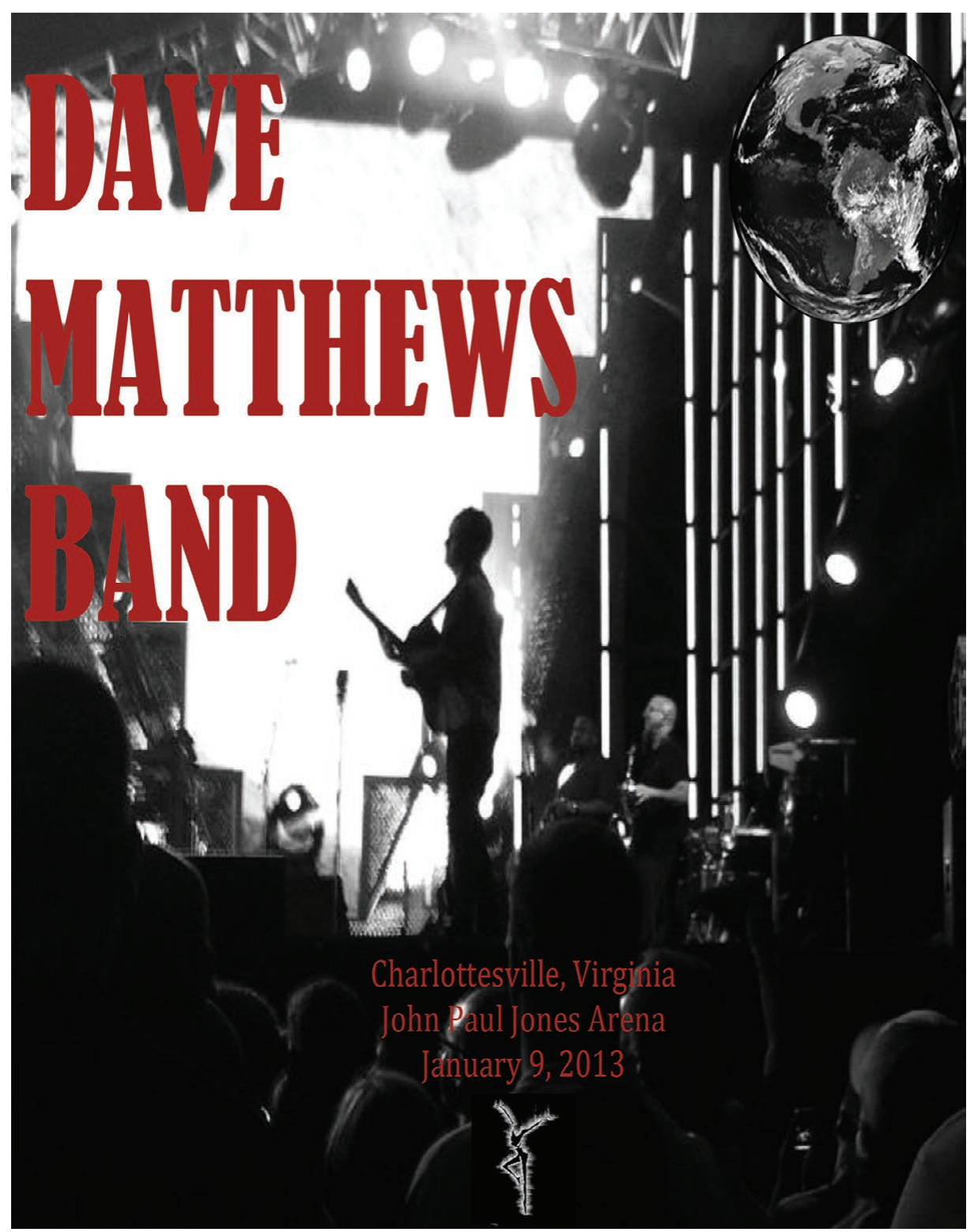

Figure 6.5. Alexa's poster for Dave Matthews Band (courtesy of Alexa Britton).

As another example, Natalie's detailed research on Demi Lovato's life directly influenced her design choices for her concert poster. Since Demi Lovato was her favorite singer, Natalie already knew the background of Lovato's struggles with emotional disorders, drugs, and alcohol abuse. By combining that knowledge 
with biographical information and interviews she read on the Internet, Natalie began to formulate a graphic representation of the singer in her mind. She connected her research with what she heard in Demi Lovato's music, associating the themes, lyrics, and music with images of fire, ashes, and shadows. Natalie chose flames as the background of the poster and applied black and white, ashen effects to a photo of Demi Lovato singing; she then positioned the ashen photo amidst the flames.

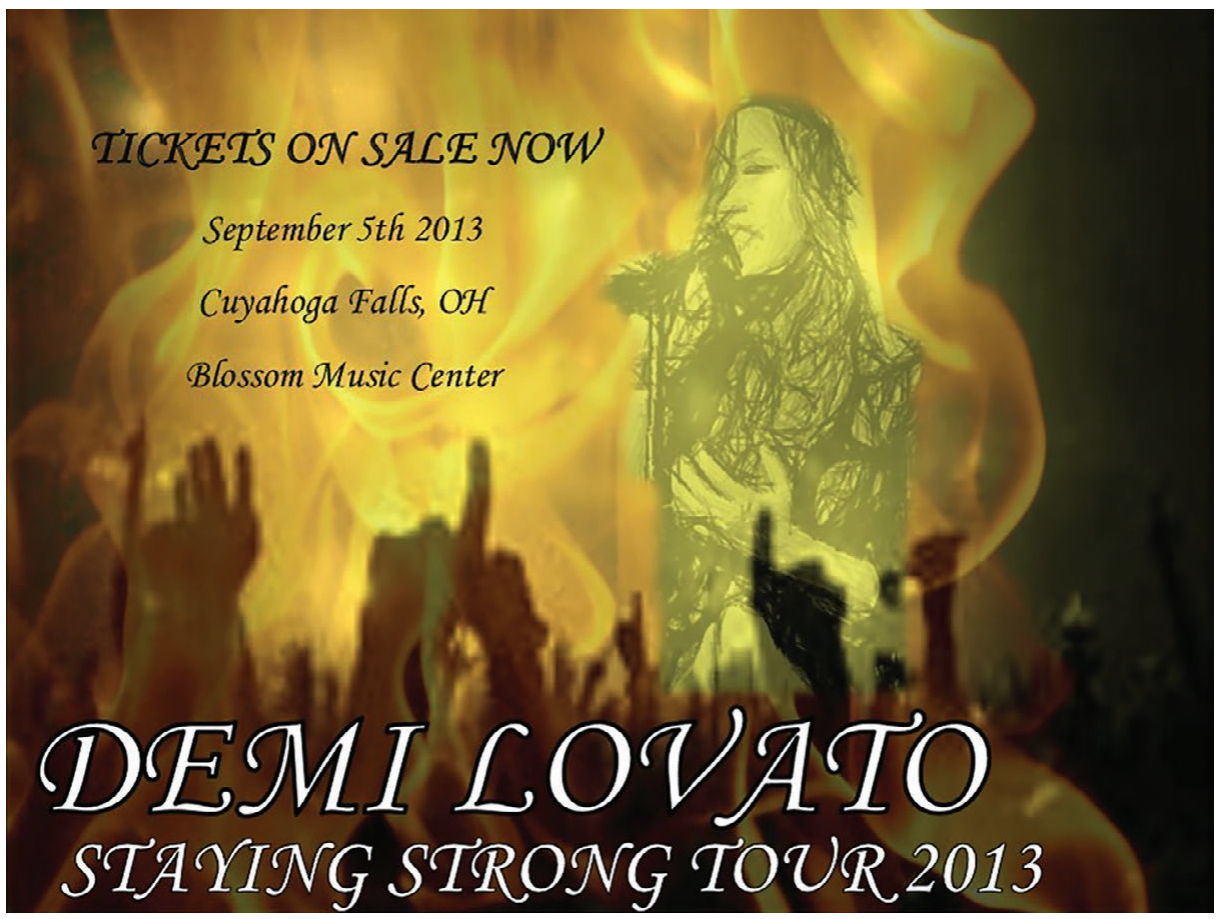

\section{Figure 6.6. Natalie's poster for Demi Lovato (courtesy of Natalie Hanna).}

Natalie's written explanation of her design choices shows that she intended for her poster to represent Demi Lovato rising from the ashes of a troubled past and rebuilding her life. Just as Demi Lovato used her music and lyrics as inspiration to recover and return to her career stronger than ever, Natalie also used the music to find inspiration for her poster-and connected with the singer's emotions in the process. In an end-of-semester reflection, Natalie wrote that in her essay, she was "able to take the message and the emotions of the artist and her music and use that as a support for my reasoning and decision making." In other words, she learned to interpret and apply research material to inform and shape her own graphic choices; and, most importantly, she closely connected her thinking, creating, and writing choices in her explanatory essay. 


\section{Connections between the Arts and Writing}

Together, the two components of this unit pave the way for students to produce writing that is more analytic and cohesive- a threshold often articulated in university assessment goals and rubrics. By engaging with the arts, students implicitly learn how active thinking, creativity, and investment in the subject matter enhance writing. This lesson often reveals itself in metacognitive reflections at the end of the semester, where many students credit this unit as the "turning point" in their understanding of what makes good academic writing and how to produce it. Shelby, for example, reflected on the concert poster unit and its process, formulating the connections between thinking, creating, and writing into an "order of activities"one which mirrors the steps in a successful writing process. She writes, "Thinking, creating, and writing are all connected; if you can do all three in that order, then writing a 6-page paper becomes a breeze." Of course, we as instructors know that students naturally progress through these three stages for every assignment across the disciplines - some just do not take time to separate them and consciously devote time to each (especially when thinking, creating, and writing are all done the night before a paper is due). However, the lesson is much more meaningful when students discover and apply it themselves. But these critical actions reinforce the idea that thinking, creating, and writing exist on a recursive continuum, and as creators and writers, students metacognitively move back and forth between stages as they complete a project. Reinforcing the importance of a process-based approach aligns with the implicit objectives of a visual rhetoric unit because students see (and hear) each stage through a medium other than words: first music, then pictures.

Above all, even I have learned (from teaching this unit and composing this chapter) that a visual rhetoric assignment implicitly invokes and synthesizes many principles of writing that are introduced in high school English courses and further developed in FYW courses. After examining the elements of the rhetorical triangle in the writing of professionals, students use and demonstrate ethos, pathos, and logos in both their posters and their essays. The Aristotelian principles of invention and style become relevant in both the visual and written stages, where students must begin by imagining, creating, and organizing graphics and end by transposing their imaginations onto paper in a language of reader-based prose. Similar to elements of presentation in writing (from paragraphing to MLA citation to logical arrangement of ideas), students adhere to principles of graphic design to ensure that fonts, colors, images, and element organization both represent the artist or band and effectively communicate to the audience. ${ }^{9}$

9 To learn more about these principles of composition and rhetoric, I suggest referencing a FirstYear Writing textbook like Everything's an Argument, mentioned earlier, or Writing Today, by Richard Johnson-Sheehan and Charles Paine. 
To conclude, I'd like to draw upon Nancy Allen's (2008) essay, "Seeing Rhetoric." She discussed the difficulties of teaching visual rhetoric, since writing and artistic creativity become separate entities as students get older. In elementary school, music, art, library, and physical education are part of every school day. As students reach middle and high school grades, though, the fine arts become more specialized choices_or simply become hobbies or extracurricular activities for some. These varied levels of interest and experience do not matter when they reach my class, though. Whether my students define themselves as "creative," "artistic," or neither, listening to music and creating concert posters represent a return to artistic exploration, innate creativity, and a youthful sense of play with colors, fonts, and graphics-activities that, as Allen believed, are by no means foreign. She wrote, "Teaching visual rhetoric, then, isn't so much teaching a new set of skills as reawakening our visual skills and developing our ways of seeing" (Allen, 2008, p. 34). Provoking my students to reawaken their engagement with popular music, create a concert poster for their favorite bands or musical artists, and then reflect on and write about their creation process and specific choices both invokes creativity and amplifies the importance of FYW's objectives and skills. Beyond having fun and learning more about visual design and music, students invade their own "nonthinking" and "nonlistening" spaces through this unit and construct a meaningful, recursive continuum between thinking, creating, and writing. And as for the winner of the debate between words and pictures, well, in first-year writing, we conclude that they are equally powerful forms of rhetoric.

\section{References}

Allen, N. (2008). Seeing rhetoric. In C. David \& A. R. Richards (Eds.), Writing the visual: A practical guide for teachers of composition and communication (pp. 32-50). West Lafayette, IN: Parlor Press.

Burch, C., \& Di Pego, G. (Producers) \& Gerald Schepisi, F. (Director). (2014). Words and pictures [Motion picture]. Germany: Roadside Attractions.

Cox, A. (2015). Mapping disciplinary values and rhetorical concerns through language: Writing instruction in the performing and visual arts. Across the Disciplines: A Journal of Language, Learning, and Academic Writing, 12. Retrieved from https://wac.colostate. edu/docs/atd/arts/cox2015.pdf

Handa, C. (2004). Placing the visual in the writing classroom. In C. Handa (Ed.), Visual rhetoric in a digital world: A critical sourcebook (pp. 1-5). Boston, MA: Bedford/St. Martin's.

Hill, C. A. (2004). The psychology of rhetorical images. In C. A. Hill \& M. Helmers (Eds.), Defining visual rhetorics (pp. 25-40). Mahwah, NJ: Lawrence Erlbaum Associates.

Hobbs, C. L. (2004). Learning from the past: Verbal and visual literacy in early modern 
rhetoric and writing pedagogy. In C. Handa (Ed.), Visual rhetoric in a digital world: $A$ critical sourcebook (pp. 55-70). Boston, MA: Bedford/St. Martin's.

Kurtyka, F. (2015). Trends, vibes, and energies: Building on students' strengths in visual composing. Across the Disciplines: A Journal of Language, Learning, and Academic Writing, 12. Retrieved from https://wac.colostate.edu/docs/atd/arts/kurtyka2015.pdf Lee, S., \& Carpenter, R. (2015). Creative thinking for $21^{\text {st }}$ century composing practices: Creativity pedagogies across disciplines. Across the Disciplines: A Journal of Language, Learning, and Academic Writing, 12. Retrieved from https://wac.colostate.edu/docs/ atd/arts/lee_carpenter2015.pdf

Mullin, J. (2011). Rhetoric: Writing, reading and producing the visual. In M. Biggs \& H. Karlsson (Eds.), The Routledge companion to research in the arts (pp. 152-166). London, UK: Routledge.

Purdy, J. P. (2014). What can design thinking offer writing studies? College Composition and Communication, 65(4), 612-641.

Rogoff, I. (2004). Studying visual culture. In C. Handa (Ed.), Visual rhetoric in a digital world: A critical sourcebook (pp. 381-394). Boston, MA: Bedford/St. Martin's.

Stroupe, C. (2004). Visualizing English: Recognizing the hybrid literacy of visual and verbal authorship on the web. In C. Handa (Ed.), Visual rhetoric in a digital world: $A$ critical sourcebook (pp. 13-37). Boston, MA: Bedford/St. Martin's.

Strovas, S. (2001). Music in the first-year writing classroom. The CEA Forum, 40(2), $24-42$.

Walters, J. L. (2010). Sound and vision. Eye, 19(76), 16-24.

\section{Appendix A. Visual Design Method Sheet for Creating Your Concert Poster}

Step 1: Initial research on the artist, album, songs, and lyrics. (Hint: keep track of your sources-you'll need that information to incorporate into your explanatory essay.

Step 2: Notes about the music itself: what genre does it fall into? What instruments? Moods? Emotions? Tempo (fast, slow, varying)? Dynamics (loud or soft)? Are there any common undercurrents in the lyrics?

Step 3: Connections_-brainstorm what comes to mind as you're putting everything together. Start with reaction words as you're listening to the music. Then, think about what colors could be associated with those words, as well as the images. Make connections between each element to push your analysis to its fullest capacity and connect written and visual rhetoric.

color
word
(ex. Calm/mellow/meditative)
-----(blue/green)




\section{Appendix B. Sequence \#3: The Culture of Concert Posters as Visual Rhetoric}

\section{Components:}

Percentage of Grade:

Draft Due for Peer Review:

Due Date:
One $81 / 2 " \times 11 "$ concert poster

6 -page explanatory essay

$15 \%$ (50 points for poster, 100 points for essay)

Tuesday, November $4^{\text {th }}$

Thursday, November $6^{\text {th }}$

Purpose: The third unit of this course moves into a genre of rhetoric that is an important, ever-present aspect of our culture: visual rhetoric. Cultural texts like web and print advertisements, commercials, cars, food, drinks, and even shopping bags overpopulate our lives, and our choices with these products contribute to our identities and make arguments about who we are as members of society. In this unit, we will focus on "reading" visual texts—in particular, concert posters. Since visual texts go through a very careful composition process, we will examine the significance of each color, font, and graphic choice and what it contributes to the poster's overall argument. You will then use that knowledge to create your own concert poster for an artist or album of your choice, and you will write a 6-page explanatory essay to accompany your poster.

Audience: Your primary audience will be the executives of the company representing the band or artist that are hiring you to design the concert poster. Obviously, they are looking for your design to appeal to fans of the artist or album you choose to advertise. How old are they? What areas of the country, economic classes, social ranks, and ways of life are they coming from? What would they know about the artist or album already?

At the same time, artists want to try and draw in new fans with their advertisements, so the executives want you to appeal to audiences that do not know the artist or album. Therefore, you'll want to pick graphics or photos that pinpoint and portray the artist or album accurately in a way that orients those who are unfamiliar with the artist to his or her music.

Assignment: The situation is this: you have been hired to design the promotional poster for your favorite artist or album, combining visual elements and words. Since you are being paid by the company to do this, they also want a 6-page typed, double-spaced explanatory essay that discusses the details of your graphic, font, and information choices and how those choices accurately represent the artist or album and impact the audience.

You'll begin by choosing a musical artist or album that is particularly meaningful to you. Identify what about that artist or album affects you so much, and figure 
out why ("because I like it" as an answer is not good enough, and will not get you anywhere with this assignment). Use those reasons (mood, emotions, messages in the lyrics, instrumentation, innovation, etc.) to locate elements of visual design that illustrate your reactions. Carefully construct your concert poster in accordance with the color schemes, graphics, fonts, and information that correspond with your reactions. Please note: your concert poster must be appropriate for an academic audience, including the graphics and the text that you choose.

After you have composed your poster, you will then write a 6-page explanatory essay that discusses the rationale behind your choices. Remember that every choice is significant, and therefore, must be explained thoroughly. What does your poster suggest to the audience about that artist or album? What elements of the artist's life, history, or music impacted you and led you to make those design choices?

\section{Evaluation Criteria}

\section{Poster:}

*images are clear, relevant, and appropriate

*colors are complementary and well-chosen

${ }^{*}$ font is appropriate

*information is organized on layout

${ }^{*}$ message is discernible
Essay:

*appropriate response to the prompt

*essay length reaches 6 full pages

* detailed explanation of visual elements

*evidence of critical thinking

*awareness of audience

* proper use of MLA format

*carefully developed paragraphs 